\title{
El espíritu de la Regla de S. Agustín en el Beato Alonso de Orozco
}

\section{Introducción}

Vaya por delante que no es la intención de estas páginas ofrecer un estudio de crítica o de interpretación de aspectos históricos, literarios o comparativ́os de estos comentarios. Lo único que se pretende es hacer resaltar el espíritu agustiniano del que se hace eco el Bto. Alonso de Orozco.

Como es bien sabido, estos comentarios salieron de la pluma del Beato el 1551 con el título de Declaración de la Regla del Bienaventurado Sant Augustin Obispo de Ypona ${ }^{1}$, y sustituyeron, en los ambientes agustinianos a la Expositio in Regulam Sti. Augustini de Hugo de San Víctor de los Canónigos Regulares.'Es el tercer comentario, en importancia, a la Regla; el segundo fue el de Umberto de Romanis, quinto maestro general de la Orden Dominicana. Después del Bto. Orozco tenemos, hasta nuestros días, otros varios que indican la estima que la Regla de san Agustín se ha merecido en el decurso del tiempo ${ }^{2}$.

El P. Agostino Vita, O.S.A., hace la observación de que todos estos comentarios presentan sus peculiaridades aun reflejando todos ellos el espíritu agustiniano. Es natural que la perspectiva del comentarista sea distinta, situados, como están, uno en el siglo XII como Hugo de S. Víctor, otro en el siglo XVI como el Bto. Orozco, y otros en tiempos más modernos. Concretándonos ahora a los dos primeros, se advierte en seguida que Hugo de $\mathrm{S}$. Víctor escribe con una cierta altura de exposición a base de abundantes citas escriturísticas y de una cierta terminología, por decirlo así, un poco más teo-

1. El texto que hemos usado fue editado en Madrid en 1781 con el título Regla de San Agustín y su exposición en castellano por el V.P. Siervo de Dios Fray Alfonso de Orozco. Ya en 1686 se había publicado una traducción en latín al principio de unas Constituciones. Los escasos ejemplares que quedaban cuando se hizo la edición que tenemos delante, obligó a una publicación en castellano usando el texto escrito por el Bto. Alonso de Orozco en 1551. En éste, la Regla que se anteponía a la Exposición se dividía en siete capítulos. En la que se publica en 1781 se divide en 12, y se sigue, en lo que a la Regla se refiere, una traducción según el texto que S. Francisco de Sales preparó para las monjas de la Visitación.

2. Vita, A., Regola di S. Agostino, Bologna 1988. Intr. p. 10. 
lógica, mientras que el Bto. Orozco hace su comentario de una manera muy sencilla y como quien se limita a hacer aclaraciones de un texto que, por lo demás, no resultaba tan oscuro a sus lectores. Era natural este modo de proceder. Hugo de S. Víctor escribe para los Canónigos Regulares; el 'Bto. Orozco se dirige a unos novicios que comienzan su formación en la vida religiosa y, además, en un tiempo de reforma de las Órdenes religiosas. Se nota inmediatamente en Orozco la intención de hacer resaltar y hacerse eco del espíritu agustiniano que él no quiere traicionar con lo que pudieran ser sus propias interpretaciones ${ }^{3}$.

De hecho, la primera impresión que se recibe al leer las páginas del Comentario es el de una suma sencillez de exposición, una profunda espiritualidad, una gran compenetración con la mente de san Agustín y con su vivencia del Evangelio; todo esto visto al través de la Regla. Estas características resaltan de una manera especial, y pueden valorarse en su auténtica objetividad, si tenemos en cuenta que el Comentario respondía, como queda dicho, a la preocupación "pastoral" que el beato Orozco tenía en relación con la "formación" espiritual.... de la vocación religiosa y agustiniana de los novicios de entonces para ayudarlos en un camino incipiente hacia la santidad. No era, pues, una cuestión de erudición. Se trataba únicamente de poner en manos de los novicios un instrumento adecuado para ir progresando en la construcción del templo de Dios que habían de llevar a cabo en sus vidas. Ya en el Prólogo, la sencilla comparación que hace de la Regla con la plomada o regla, que usarían sin duda ya entonces los albañiles constantemente en la construcción de las paredes para que resultasen sin inclinación alguna, nos indica la única finalidad que se propuso al escribir el Comentario:

. "Así como hay muchos edificios y obras que parecen estar a plomo y nivel, y echando la regla se ve la falta y se conocen las paredes que van acostadas a una parte, por donde peligra el edificio, de la misma manera, aunque os parezca ir vuestras obras bien acertadas, si las niveláis y medís con esta Regla de nuestro Padre, hallaréis en ella qué mejorar y perfeccionar" (Prólogo al lector).

Esta preocupación va unida a la de que el noyicio que llama a las puertas del convento agustiniano, "a donde Dios los trajo para servirle y amarle", sea ayudado a adherirse a la familia agustiniana y a amarla, ya que en ella "han sido muy perfectos los religiosos que la han seguido", y han vivido según la Regla de tan gran Padre (Ib.).

3. Ni siquiera aducirá textos de las obras de $\mathrm{S}$. Agustín, apenas lo cita un par de veces, limitándose a una simple explicación de la Regla. 


\section{El ejercicio del amor a Dios y al prójimo como contenido esencial de la Regla}

Ya desde el principio el Bto. Alonso de Orozco dejará bien claro a los novicios que la Regla que intenta exponerles es en realidad una "regla divina", ya que la estructuración de dicha regla, que es obra de Agustín, se fundamenta y desarrolla según dos conceptos o preceptos "dados por la mano omnipotente de Dios y declarados y obrados por nuestro Salvador Jesucristo para nuestro ejemplo" (c. I,2). Con todo el derecho nos impone el Señor estos preceptos, ya que tiene un derecho de conquista sobre los hombres:

"De manera que así como el que gana alguna ciudad impone el pecho y servicio que de ella quiere, por lo mucho que gastó y trabajó para ganarla, así nuestro Redentor Jesucristo, habiendo dado su sangre, su honra y su vida muriendo en la Cruz por nosotros, un mandamiento nuevo nos dijo que hos mandaba, y esto es: que nos amemos unos a otros como él nos amó en Dios y por Dios" (c. I,3).

A nuestro comentarista le parece muy natural que a san Agustín no se le ocurriese otra síntesis de conducta para sus seguidores que la que expresan las primeras palabras con las que comienza la Regla "cuando dice que ante todas las cosas amemos a Dios y al prójimo" (Ib.). Estos dos preceptos sobre el amor a Dios y al prójimo, que se traducen en unanimidad de alma y de corazones hacia Dios, son toda la razón de ser y de vivir de la comunidad:

"Somos llamados a la religión, no para que nos vistamos solamente de un paño, comamos a una mesa, oremos juntos en coro y en todo lo de fuera seamos unos" (c. I,4).

No quiere decirnos el Beato que esto no tenga su importancia, pero "no ha de parar ahí nuestra religión sino en la unidad del corazón y en ser unos en el espíritu, amándonos en Dios" (Ib. 6). Si Sodoma y Gomorra, nos recordará, no alcanzaron misericordia, fue porque en medio de ellas no hubo siquiera diez justos, una pequeña comunidad de amor capaz de mantener en medio de ellas el Señor. Agustín intentará, nos dice, "despertar aquella imagen viva de la primitiva iglesia" donde "eran todos de un alma y de un corazón en Dios" (Ib.). Siempre la mente agustiniana de que, siendo de Dios, hemos de vivir con Dios y para Dios, para un día ser Dios.

Aunque nos acaba de decir que lo que externamente nos une no es la razón de vivir en comunidad, sin embargo, la propiedad de los bienes ha sido siempre reconocida, ya desde Platón -nos recuerda el Beato- como un posible impedimento de lo que es la auténtica razón de la vida comunitaria, donde el "lenguaje de propiedad", de "mío" y "tuyo" es un reconocido impedimento de la paz. A fortiori valdrá esto en "la casa de Jesucristo para 
tener pacífica el alma y para imitar la pobreza del Padre de los pobres nuestro Redentor" (Ib. 8). Es, precisamente, en función de una completa dedicación a sí mismo, como María al servicio de Dios, el que se nos recomiende reducir las cosas de que hemos menester, es decir, nuestra preocupación por ellas, para, así, estar menos atados y más libres para la contemplación. Es aquí donde entra la suplencia del Superior a quien se le encomienda mirar por las necesidades de los hermanos:

"Harta merced nos hace el Señor, que nuestros prelados ejerciten la vida de Marta; nosotros elijamos luego la parte que nos cabe, descuidándonos de todo e imitando la inquietud y contemplación de María a los pies del dulcísimo Jesús" (c. I,13).

Así, desde la humildad de nuestra pobreza de bienes materiales, pobreza que ha de llevar consigo la despreocupación o desprendimiento interior, podremos "comenzar a contemplar su sagrada humanidad para que, de allí, sea nuestra alma elevada a lo alto de su admirable divinidad con maravilloso contentamiento y gusto" (Ib.). En estas sencillas y breves palabras está reflejando nuestro comentarista el pensamiento de san Agustín cuando nos indicaba que era absolutamente necesaria la continua búsqueda de Dios mediante una vida contemplativa requerida para una conversión total a Cristo, y para que el religioso esté capacitado para ser un hombre de oración (In ps. 104,3). Entonces, esa humildad de la pobreza, que no despreciará a ningún hermano por razón de la falta de bienes, y ese encuentro con Dios que nos hará vivir de lo que es auténtico, constituirá a la comunidad en templo de Dios y, por lo mismo, en una auténtica comunidad agustiniana. Este aprecio de los demás hermanos como algo de Dios será la gran alegría del que así honra a los hermanos honrándose a sí mismo.

La oración como realización en la vida religiosa agustiniana del precepto del amor a Dios

Alonso de Orozco, al comentar el cap. II de la Regla, trae a cuento las palabras de Isaías: "Yo los traeré a mi monte santo y los alegraré en mi casa de oración" (Is 36,7), aplicándolas al monasterio "casa de oración así intitulado" (c. II,1). Pero enseguida nos advierte que esto será verdad siempre y cuando "el religioso entienda en su oficio principal, que es orar" (Ib.), para constituir a la comunidad en el verdadero templo del Señor. Así se hace eco del templo agustiniano comunitario por el amor: "Todos conjuntamente somos templo de Dios y cada uno en particular somos templo suyo. Él se digna habitar en la concordia de cada uno" (La Ciudad de Dios, X,3,21). Esta concordia, según Agustín, constituye "la buena orquesta donde hay 
muchos instrumentos cuidadosamente ajustados y entonados que la audiencia oye en una sola melodía, una orquesta para el Señor" (In ps., 105,6), que es la auténtica oración de alabanza a Dios: "alabad al Señor como un coro; fusionad vuestras voces por medio del amor fraterno" (In ps., 149,7). Así, si antes se trataba de la unión en comunidad desde la propiedad de bienes, es ahora la unión de corazones hacia Dios (oración como búsqueda de Dios) lo que completará la construcción del templo de Dios. Ahora entendemos que el Bto. Orozco nos diga en su comentario que esa oración del religioso ha de ser "muy continuamente":

"Quien cesa de orar, da favor a sus enemigos, y es como el que se rinde, dejándose atar las manos. Luego cumple siempre orar, como dice el Señor, y no cansarse en la oración" (c. II,3).

De nuevo enlaza aquí con Agustín en lo que la oración tiene de reencuentro con Dios. Y a este respecto no olvidamos lo que Juan Pablo II no hace mucho decía sobre san Agustín calificándolo, no como hombre de oración, sino como "hecho de oración" " ${ }^{4}$. En efecto, Agustín nos señala unos pasos en la oración que comienzan con la oración vocal que nos "invita" a desear, nos "ejercita" en el desear, nos "amonesta" a adquirir conciencia en el progreso del deseo, nos "enardece" en el deseo y nos "anima" a ejecutarlo (Epist. 130) para que Dios "habite" en nosotros para que "vivamos en la bondad", en la "verdad", en la "justicia", en la "purificación" del corazón y en la unión y "conversación" con Dios (Serm. 232, 277, 278). De este hombre "hecho de oración" heredó el Bto. Orozco lo que pedía a los novicios cuando les decía:

"Siempre ora el que siempre ama a Dios, y siempre contempla el que sube su corazón a las cosas eternas y celestiales; finalmente siempre está en oración... el que obra cosas provechosas y buenas" (c. II,4).

Y siempre en consonancia con esa oración que era como el alma de la vida de Agustín, el Bto. Orozco tiene un inciso que responde a esa realidad agustiniana cuando nos dice hablando del oratorio: "De aquí es que en el oratorio, que es la celda...". Evidentemente la celda era entonces el lugar habitual donde se desenvolvía la vida del religioso y también su trabajo, en la que "nadie ha de hacer otra cosa que lo que responde a su nombre... y no ha de haber ruido ni golpes que inquieten a los que hablan con Dios" (Ib. 6) indicándonos que la vida toda del religioso ha de ser oración. En cambio, en el oratorio que es la iglesia entiende el Beato que es el lugar para orar en el sentido exclusivo, ya que "en él... solamente se ha de entender en cosas espirituales". Este oratorio en sentido material "no limita la oración, sino que

4. Carta Apostólica "Augustinum hipponensem", de 28 de agosto de 1986. 
mueve al que ora porque, como es lugar para orar dedicado, despierta y mueve a devoción" (Ib.).

\section{La oración vocal y mental como camino hacia una vida de oración}

Hay una oración vocal, oficial en la Iglesia, y que ésta "tiene ordenada a base de Salmos e Himnos". Es Dios el inspirador de los salmos, por lo que podemos considerar esta oración como la oración vocal por excelencia con la que "damos música a Dios con la oración que Él mismo nos ordena (c. II,9). Pero se trata aquí de una oración que hay que hacer "con arte" que consiste en "que lo que se dice con la boca eso mismo se trate con el corazón". Esto quien decir que la lengua del espíritu, la atención, ande junta con la lengua exterior del cuerpo" (Ib.). Para que esta oración vocal surta sus efectos como alimento del alma debe hacerse según una especie de "rumiación". Trae a cuento a este propósito el cap. II,3 del Levítico en el que se refieren las condiciones que tenía que tener el animal que se sacrificaba al Señor, entre las cuales estaba la de ser "rumiante":

"Los siervos de Dios, cuando oran atentamente, rumian, sacando con afecto y maravilloso gusto la oración de lo interior de su corazón hablando con la boca las alabanzas divinas" (Ib. 10).

Otra cosa es cuando se trata de la oración mental para la que no sirve este aviso porque entonces la mente es con la que el alma se dirige a Dios buscándole con el deseo desde la interioridad. En este caso hay que contar con un enemigo que es la "vagueación" de la mente, que "suele turbar a muchos en el tiempo de la oración cuando, queriendo y deseando estar más atentos, se hallan pensando en los negocios que son obligados a tratar, y aun a las veces, cosas superfluas" (Ib. 12). Sin embargo, esta falta de atención, "cuando voluntariamente no se distrae el que ora", no impide dos de los tres frutos de la oración. Precisamente, porque entonces tiene una ocasión de humillarse por su flaqueza y, por otra parte, de ejercitarse en la lucha "ojeando aquellas moscas importunas con el palo de la santa Cruz y memoria de la pasión de Jesucristo", a semejanza de "Abraham cuando ofrecía sacrificios a Dios y las aves se lo querían arrebatar" (Ib. 13); esto sería ya un mérito y un primer fruto de esa oración. Tampoco se le impediría un segundo fruto que es "alcanzar lo que se pide, si es cosa que nos conviene recibirla". Lo único que no conseguiríamos sería el tercer fruto: que "el alma guste con gran suavidad de Dios, con el cual conversa y habla orando". Por eso no hay que descuidar, en cuanto se pueda, la atención "en el tiempo que hablamos con Dios, porque no sólo merezcamos orando, más aun gustemos cuán suave es el Señor" (Ib. 14). 
La mortificación y pobreza como principios negativos que posibilitan el encuentro con Dios

Finalmente, algo que nuestro comentarista subentiende como pensamiento de san Agustín y relacionado con una vida de oración es la mortificación en sus aspectos de ayuno y abstinencia; sus palabras son éstas: "finalmente en este capítulo nuestro Padre dice que nos dispongamos para la oración siendo abstinentes y ayunando". Aquí la mortificación no habría que entenderla "como un fin" en sí, por eso nos concretará los modos de la misma. Y si, a veces, santos como san Nicolás de Tolentino parecen "seguir extremos" en cuestión de mortificación, "entendamos ser espíritu de Dios que los guió para nuestro ejemplo y para que en ellos loemos a Cristo que tanta virtud les dio" (c. III,16). Es precisamente en la mortificación como negación de sí mismo en lo que se revela la riqueza del religioso, que se vacía de lo que en el mundo se considera como riqueza y así se capacita para gustar la vida de Dios, llena ese vacío y es riqueza de Dios... "Cada día crece más en riquezas el alma del religioso pobre, imitador de la pobreza evangélica" (Ib. 19).

El capítulo referente a los vestidos es enfocado desde una pobreza que significaba algo que no iba con la grandeza de ese mundo del que el religioso se ha retirado. Es propio de los que "viven en las casas de los Reyes de la tierra" el andar muy ataviados y bien vestidos para no desentonar. Pero "los que se precian de vestiduras delicadas no son de mi casa". Al religioso, cuya vida ha de ser predicación y ejemplo de pobreza, no le conviene andar vestido de hábito precioso... para ser testigo de la pobreza que profesó" (c. III 1y 2). Esto parecería no tener relación con el asunto de una vida de oración; al contrario, según Aḷonso de Orozco, una vida de oración, de fraternidad, en contraste con un mundo en el que hay que vivir, pero al que no hay que asimilar, le lleva al religioso a prescindir de todo aquello que es algo que impide, ocupando el corazón, como las riquezas, o que es signo de una grandeza o vanidad que no va con la humildad religiosa. En otras palabras: el religioso es un constructor del templo de Dios y en ese templo ha de consagrar toda una vida al encuentro con Dios en la oración y en el trabajo como realización de un plan de Dios en un mundo al que ha renunciado y del que ha de defenderse. La misma idea de una vida consagrada a Dios preside lo que serían meras reglas de conducta externa, quizás hoy no compatibles, como la de salir de casa en compañía de un hermano, etc.; hay que interpretarlas siempre como algo que va con el hombre de oración que es el religioso, 
entendiéndolas desde la unidad y fraternidad en la ayuda mutua y edificación de los cristianós... (c. III,3 y 4).

Otro caso parecido sería el de la relación con las mujeres. Bien se sabía san Agustín tras lo que se andaba al escribir el cap. VI de la Regla. Sin haber cursado ningún curso de psicología era un estupendo conocedor del espíritu humano. No se trata de mirar o no mirar a las mujeres, sino de que la alternativa total, que hace al religioso ser una realidad de fidelidad a Cristo, pueda ponerse en entredicho si se permite que el deseo, fácilmente consecuente con ciertas miradas, sea algo admitido por el religioso. A esta fina psicología agustiniana responde el comentario de Orozco: "el concierto que tenía él hecho (se refiere a Job) ha de hacer el avisado religioso si no quiere verse con la batalla y aun en peligro de ser vencido en ella. Tenga aviso de no mirar y quitará armas al enemigo..." (Ib. 6).

Y no es cuestión de achacar al Beato timideces, beatuquerías o tabúes de cualquier género; distinguía muy bien entre los religiosos corrientes y molientes,. buenos sin duda, y aquellos "varones espirituales (en los que) ya está tan muerta toda mala inclinación que, sin daño alguno mirando, ven como aquellos "ciegos" evangélicos que veían hombres como árboles andando. Son los hombres de oración que han venido a gozar de tan celestial privilegio: en manera que ya cuasi sienten una centella de aquel señorío que el alma tendrá en la resurrección de su cuerpo, no siendo en él en cosa alguna rebelde el espíritu" (c. III,9).

Pero porque son los más "los que tienen necesidad de guardarse y recelarse aun de sí mismos, no estando seguros en tanto que vive Dalila (así llama el Beato al cuerpo de pecado de san Pablo), se pone en el consejo saludable (de) que cada uno guarde el homenaje de su corazón pues de él resulta la vida" (Ib.).

El ejercicio del amor al prójimo como salvaguarda del templo de Dios que son los individuos y la comunidad

Aparte del deber que todos tenemos de mirar por el bien de los demás, no como policías vigilantes sino como quien ama lo que es suyo, Alonso de Orozco hace resaltar en el pensamiento agustiniano que esta vivencia en el amor de Dios y al prójimo es la única razón para mirar los unos por los otros: "Aquí es menester gran espíritu y gran miramiento, y del descuido en esto habrá estrecha cuenta para con Dios". "Los dos religiosos que salen del monasterio... míranse como querubines (alude a los dos querubines del Arca) cuando cada uno guarda y mira las faltas del hermano y se las corrige..." (c. III,4 y 5). Aplicado a la corrección fraterna, sólo un completo amor 
y respeto al que yerra, como el que pide el evangelio "dando regla de cómo se ha de guardar la honra y fama del prójimo, la cual, después de todo, es el mejor tesoro que el hombre posee" (Ib.), facilita tan difícil actuación. Este es el espíritu que preside también la recomendación que se hace al prelado como responsable de la buena dirección de los súbditos. Lo que quedará siempre en pie es lo que implican estas recomendaciones, es decir, que ninguna alternativa pueda ofrecerse a la vida religiosa que impida el que "del todo esté descuidado el siervo de Dios, en una sola cosa entendiendo, que es servir y amar a Jesucristo, en el cual debe poner todo su cuidado"; esto por parte del amor a Dios. Por razón del amor al prójimo, el mirar por el bien común como si fuera propio es la manera de poder "ser el religioso pobre imitador del pobre y rico Jesucristo (y no) un Judas propietario" (c. IV,1).

\section{Las enfermedades de los hermanos, enfermedades de Cristo}

Alonso de Orozco apela a la realidad del cuerpo místico de Cristo para enfocar el problema del cuidado de los enfermos por amor a Cristo:

"Jamás nuestro Redentor estuvo en cama con calenturas, ni otra enfermedad, porque, aunque quiso padecer hambre, y sed, y dolores y muerte, no tuvo por bien de sufrir otras enfermedades que a nosotros nos atormentan: luego enferma en sus miembros, y padece necesidad de consuelo en sus fieles; y esta es la queja muy justa que de nosotros da" (c. IV,8).

Pero también recuerda a los enfermos que la enfermedad demuestra el grado de perfección; es una piedra de toque que nos cerciora sobre nuestras reservas espirituales. Las privaciones que los hermanos tienen que sufrir a pesar de los cuidados de los hermanos y del superior, entran dentro de una Providencia de Dios y deben servirnos para tener presente y contemplar en toda circunstancia a Jesucristo el Padre de los pobres. Nunca se le escapa a nuestro comentarista enjuiciar toda vivencia religiosa desde la luz de Dios. Y ni podía serlo menos el problema del servicio comunitario, sea el que fuere este servicio. El convento es la casa de Dios y los quehaceres comunitarios son la realización del proyecto de Dios, en los que los religiosos son causas coordinadas para conseguir lo que Él se ha propuesto en sus planes de salvación:

"La casa religiosa es la casa de Dios; todos_los oficios en ella son nobles_ pues la obediencia todo lo engrandece y levanta" (Ib. 11).

Todo se reduce a una cuestión de humildad y caridad. Si existen estas dos virtudes funcionará bien la comunidad:

"Mucho merece el que va al coro y el que predica la palabra divina; mas no menos merece el que tiene oficio de vida activa... Y aun quiero decir más, 
que el que en oficio de vida activa sirve con humildad y con caridad ese tal tiene su mérito por ventura más seguro que no el que entiende en la vida contemplativa siendo negligente" (ib. 11).

\section{La concordia y la paz fruto de la comunión fraterna}

Paz a vosotros, repetía Jesús resucitado, una paz que era como el fruto de su pasión:

"Razón es que tengáis unidad, y paz, pues veis mis manos, y pies, y costado, lo que me cuesta poneros en paz con mi Padre celestial. Yo vencí la guerra...; con mi sangre maté los fuegos de las iras y litigios; gustad, pues de la paz que en tan baja guerra os tengo ganada" (c. IV,1).

Pero si Cristo nos ganó la paz con el Padre Celestial, tenemos que conquistarla continuamente porque "la gente carnal, los que andan según el hombre viejo que es este cuerpo sensual" (Ib. 3), son el pan de cada día para el hombre a causa del "cuerpo de pecado" de que nos habla san Pablo (Rm 8) y que origina las contiendas. Contra esto hay que reaccionar a base de humildad y de ejercicio del silencio:

"El alma que no ha llegado a gran humildad, no podrá ser ella del todo paciente, porque de conocer nosotros nuestra poquedad, nos viene el que seamos sufridos, y aun que nos gocemos con ser menospreciados, y maltratados... Nosotros bien hijos de Adán, habiendo de resistir nuestras pasiones, abrímosles la puerta, injuriando y maltratando a nuestros hermanos con poca ocasión y aun muchas veces sin porqué" (Ib. 5).

Y si no hemos sabido ser humildes y callados a tiempo, "que la lengua (que) hizo las llagas injuriando a su hermano, que ella sane la herida que dio, pidiendo perdón y humillándose delante del que fue ofendido" (Ib.6). De lo contrario no hay que hacerse ilusiones de una vida religiosa decente, ya que la situación de contienda "mucho turba el alma para la quietud de la contemplación e impide para el gusto de Dios en la oración" (Ib.). El evangelio habla claro al Bto. Orozco: "ni hijo de Dios ni heredero del cielo no queriendo ser hermano de tu prójimo, por quien el Hijo de Dios murió en la Cruz" (Ib. 7). En la mutua ofensa, mutuo perdón, y "será más perfecto el que se humilla adelantándose. El que no quiere pedir perdón es como una estatua con hábito de monje" (Ib. 8). En el caso del superior no debe olvidarse que ha de ser "aceite de misericordia y vino de justicia (Ib. 10) hasta quizás teniendo que contar con palabras ásperas. Dada la condición humana, aun los perfectos pueden excederse, aunque desde el buen celo. No deberá pedir perdón al súbdito, aunque "merecería mucho en ello" y vendría bien a todos. 
Lo que hace falta y es absolutamente necesario es que el superior gobierne amando, es decir, con "suavidad y benignidad" (Ib. 11 y 12).

A propósito de la postura del superior como "guía y pastor que ha de dar cuenta de las almas de sus súbditos", el prelado no debe olvidar que es como atalaya puesta por Dios, según las palabras de Ezequiel $(17,18)$. El Bto. Orozco piensa que las palabras de Ezequiel son palabras que deben hacer que todos huyan de la ambición de los puestos de mando:

"Esta amenaza hace temblar el corazón de los que rigen, y esta éspada tan temerosa los admira y los atormenta, para que comiendo no coman, durmiendo no reposen y duerman ¡Oh! pluguiese a Dios que todos los que desean mandar, y los que Dios a su profeta dijo, y cada día dice a sus Prelados: el súbdito se condenará no le corrigiendo y guardando tú; y a tu cuenta y para tu condenación será tu perdición. Entendido tengo que la ambición de los hijos de Adam perecería, y que las Prelacías se llevarían como cruces pesadas, por fuerza y no por voluntad" (c. VII,5).

Es decir, no es cuestión de servirse de, sino de servir a: "el buen Prelado no ha de tener su contento en cosa tan baja, antes ha de huir como Cristo huyó cuando le quisieron hacer Rey" (Ib. 11). El Bto. Orozco piensa que el que acepta una prelacía ha de atender a tres razones para no equivocarse: $1^{a}$ ) el ser llamado por Dios para ese servicio: "entiendan que Dios los llama para aquel oficio; y sin ellos entender en ello, ni aun quererlo, son elegidos para tales oficios" $2^{a}$ ) la caridad a causa de la necesidad, según aquello de Agustín: "la quietud santa de la oración y contemplación busca la caridad; y la ocupación justa recibe la necesidad, a la cual obliga la misma caridad" ( $D e$ civ. Dei, 19,19); y esto es más perfecto que lo primero. $3^{\text {a) }}$ "el ser ordenado por la obediencia: y esto es más alto motivo que todos" (Ib. 13). Y, por si acaso, los superiores no deberían olvidar que los súbditos tienen los ojos que bien abiertos: "como no haya cosa en que más los súbditos pongan los ojos que en el tratamiento que el Prelado hace de sí mismo. En él quieren ver la pobreza que la Regla manda; en él buscan la humildad y obediencia, y, finalmente, en él, como en dechado, quieren hallar todas las virtudes y perfección de la religión" (Ib. 16). Pero, a la vez, no hay que olvidar la postura que los súbditos deben tener para con los superiores. A ellos se les dice y muy claro que "si en el siglo eras servido y acá lo quieres ser, ¿qué dejaste por Jesucristo tomando el hábito y prometiendo pobreza? (Ib. 18), a los súbditos se les recuerda el respeto a sus superiores en

"iporfía admirable! Que nosotros los levantemos sobre nuestras cabezas, y que ellos se derriben a nuestros pies; nuestro cuidado sea tenerlos como a señores, y ellos entiendan de tenernos como a hermanos; finalmente, que 
nosotros nos desvelemos en amarlos, y obedecerlos como a Padres, y ellos estudien en hacernos tratamiento de hijos. Tales Prelados y tales súbditos más diremos que viven vida del cielo que de la tierra" (Ib. 20).

Estando así las cosas, ya puede aventurarse el superior ya que acompañará la reprensión con el ejemplo: "mucho hace el hablar amonestando y avisando a los súbditos; mas muy mayor eficacia tiene el obrar" (Ib. 21). Es toda una tarea de un programa perfecto para gobernar amando lo que tenemos en los números 2.1-30 de este capítulo VII.

La Regla, desde la obediencia, como libro de vida y medio indispensable de perfección

Ya en su Instrucción a los religiosos había tratado el Bto. Orozco este punto. Aquí se limita a recordar desde la Escritura (1R y Lc 10,16), sobre todo desde el ejemplo de Jesús, que es a Dios a quien se obedece o desobedece en el prelado: "no te menospreciaron a ti sino a mí; tu injuria a mi cuenta se pone y a mi Majestad se hace" (c. VI,2). Por otra parte la obediencia es indispensable para cantar victoria. Hace aquí una alusión a una jerarquía de valores y a que de perfectos es salir al encuentro de la obediencia cuando ésta nos consta en la voluntad del superior sin esperar a que "saque la espada del alma, que es el mandamiento" (Ib. 4).

Pero inútil sería esta Regla y todas las habidas y por haber si se tuvieran muy bien en la memoria y no se llevasen a la práctica. Muchos, dicen al oír la Regla lo que dijeron los israelitas (Ex 19,7 y 8): "todo lo que nos manda Dios haremos", para hacer después lo que les viene en gana:

"Los descuidados, que no miran lo que prometieron en la Regla, ni se precian de enmendar sus faltas considerando que vinieron a vivir la vida apostólica y a ser varones perfectos y no a seguir y a imitar a los descuidados y negligentes" (c. VII,2).

La responsabilidad en el cumplimiento de la Regla está en relación con lo preceptuado en la misma. ¿A qué nos obliga? ¿Quizás a pecado grave? En esta caso habría que pensar que "sería más peligroso vivir en la Religión y tendría mayor peligro de perderse el religioso que el que queda en el mundo" (Ib. 6). Orozco, siguiendo a Sto. Tomás (I-II, q. 186, a. 9), distingue lo que es el fin y perfección a la que tiende el religioso de lo que son los medios para alcanzar esa perfección. Ahora bien, el religioso no está obligado a ser perfecto, "aunque siempre le cumple desear y trabajar de alcanzar la perfección; de aquí que solamente obligue la Regla a los tres votos de pobreza, castidad y obediencia; mas de todo lo que no contraríe a estos votos, no se da en la Regla sino consejo. En manera que será regla universal: que 
nuestra Regla no nos obliga más de lo que los mandamientos de Dios obligan a cada cristiano, y a la observancia de los tres votos, en los cuales está la esencia de la Religión" (Ib. 7). Otra cosa sería el no guardar la Regla por menosprecio de la misma: "per contemptum". Es pecar por menosprecio "no querer hacer alguna cosa precisamente porque lo manda la Regla, la Constitución o el Prelado" (Ib. 10). Pero no lo es "el descuido, ni la flaqueza, ni la costumbre..., ni quebrantar muchas veces el silencio, ni ir muchas veces tarde a Coro" (Ib.). Téngase, sin embargo, muy en cuenta qụe este modo de comportarse "dispone para ese menosprecio, para venir a quebrantarlas por menosprecio" (Ib.) A esto contribuiría también una postura de "desabrimiento con su Prelado". Es claro, pues, que el Beato intentó deslindar muy bien lo que jurídicamente podía constituir un pecado grave contra la Regla, de lo que sería en la realidad una situación de vida religiosa imperfecta, al mismo tiempo que insiste en la conciencia que todo religioso debe tener de tender a la perfección.

Oración de Agustín encomendando al Señor el buen quehacer de sus seguidores

"Concédaos el Señor...". Agustín, siguiendo el ejemplo de Pablo (Rm $16,24)$, pide por los que han de ser sus hijos para que puedan secundar siempre un fiel cumplimiento de la Regla. Tanto los que no hacen esto (Ib. 31) como los que cumplen a medias (Ib. 33) son amonestados a librarse los primeros de "un gran verdugo que es nuestro propio querer", y a no ser, los segundos, "estatuas y no religiosos que no tienen más que el hábito..., hombre fingido y no verdadero... que no tiene más que las muestras de fuera" (Ib. 32). De esta manera puede darse un buen olor de Cristo, dando lugar a que "nuestros deseos santos sean el azahar que trascienda hasta el cielo, y aun penetre los cielos" (Ib. 35). Pero todo este cumplimiento de la Regla ha de hacerse en la libertad de los hijos de Dios y no con conciencia de esclavos; es condición indispensable para permanecer en la buena obra que se comenzó, teniendo siempre en cuenta que la Regla será siempre el espejo que acuse las desviaciones: "delante del espejo se atavía el rostro, y con la Regla delante de los ojos, y acordándonos de lo que se nos manda, ataviemos nuestra alma" (Ib. 39); lo que mucho vale ha de ser con gran cuidado guardado y solicitado" (Ib. 40).

Las últimas páginas de estos comentarios son una invitación a ser agradecidos con Dios que. "quiere que el provecho sea para nosotros, y la gloria manda que sea para él" (Ib 41), haciéndose así más capaces de mayores tesoros (Ib. 43). Por lo demás, supuesta la penitencia y enmienda de los pecados pasados y el propósito para el futuro, la "oración humilde alcanzará el per- 
dón y la perseverancia y la fuerza para soportar la tentación, de la que no hay que pedir la desaparición, lo que sería equivalente a "pedir los dos asientos que Juan y Santiago pidieron" (Ib. 51).

Concluyendo: un aviso recordando que la soberbia y demás pecados capitales serán el "combate cotidiano" en el que "hemos, con hervor y humildad, de suplicar que no seamos vencidos" (Ib.).

Fidel CASADO 